\title{
Brief Introduction of Carbon Neutral International Organizations
}

\author{
Wang $\operatorname{xin}^{1},{ }^{*}$, Ma Cuifeng ${ }^{1}$ \\ ${ }^{1}$ National Geological Library of China, 100083 Beijing, China
}

\begin{abstract}
We searched the yearbook database of international organizations with "carbon" and " $\mathrm{CO}_{2}$ " as key words, and got six international organizations related to carbon neutrality on the basis of cleaning the data. This paper will briefly introduce six carbon neutral international organizations included in the Yearbook database of international organizations to provide references for researchers.
\end{abstract}

\section{Introduction}

At the general debate of the 75th UN General Assembly held on September 22, 2020, China announced to the world that it would enhance its national independent contribution. The emissions of the carbon dioxide will reach the peak by 2030 by taking more effective policies and measures, and the carbon neutrality will be realized by 2060. It has aroused wide discussion and attention of global researchers and policy makers on carbon neutrality after the goal was put forward[1]. This paper will briefly introduce six carbon neutral international organizations included in the Yearbook database of international organizations to provide references for researchers.

\section{Methods and Materials}

The $\sim 66,000$ international organizations maintained in Yearbook database of international organizations include Intergovernmental Organizations (IGOs) and International Nongovernmental Organizations (INGOs) in 300 countries and territories. Approximately 1,200 new organizations are added each year[2].

We searched the yearbook database of international organizations with "carbon" and " $\mathrm{CO}_{2}$ " as key words, and got six international organizations related to carbon neutrality on the basis of cleaning the data. We briefly introduced the establishment time, place, mission, member structure and activities of these organizations. See Table 1 for details.

Table 1. Six Carbon Neutral International Organizations.

\begin{tabular}{|l|c|c|c|}
\hline \multicolumn{1}{|c|}{ Name } & $\begin{array}{c}\text { Founded } \\
\text { Time }\end{array}$ & City HQ & $\begin{array}{l}\text { Country/ } \\
\text { Territory } \\
\text { HQ }\end{array}$ \\
\hline $\begin{array}{l}\text { European } \\
\text { Network of } \\
\text { Excellence on } \\
\text { the Geological } \\
\text { Storage of } \\
\mathrm{CO}_{2}\end{array}$ & 2004 & Orléans & France \\
\hline $\begin{array}{l}\text { Global CCS } \\
\text { Institute }\end{array}$ & 2009 & $\begin{array}{c}\text { Melbourne } \\
\text { VIC }\end{array}$ & Australia \\
\hline
\end{tabular}

\footnotetext{
" Corresponding author: 357941967@qq.com
}

\begin{tabular}{|l|l|l|l|}
\hline $\begin{array}{l}\text { International } \\
\text { Institute for } \\
\text { Carbon- } \\
\text { Neutral }\end{array}$ & 2010 & Fukuoka & Japan \\
$\begin{array}{l}\text { Energy } \\
\text { Research }\end{array}$ & & & \\
\hline $\begin{array}{l}\text { Carbon } \\
\text { Offsets To } \\
\text { Alleviate } \\
\text { Poverty }\end{array}$ & 2011 & $\begin{array}{c}\text { Oakland } \\
\text { CA }\end{array}$ & USA \\
\hline $\begin{array}{l}\text { International } \\
\text { Sustainability } \\
\text { and Carbon } \\
\text { Certification }\end{array}$ & 2011 & Cologne & Germany \\
\hline $\begin{array}{l}\text { Carbon } \\
\text { Neutral Cities } \\
\text { Alliance }\end{array}$ & 2014 & Network & Network \\
\hline
\end{tabular}

\section{International Organizations about Carbon Neutral}

\subsection{European Network of Excellence on the Geological Storage of $\mathrm{CO}_{2}\left(\mathrm{CO}_{2} \mathrm{GeoNet}\right)$}

\subsubsection{Founded}

European Network of Excellence on the Geological Storage of $\mathrm{CO}_{2}\left(\mathrm{CO}_{2} \mathrm{GeoNet}\right)$ was founded in Venice (Italy) in April, 2004[3].

\subsubsection{Mission}

The mission of $\mathrm{CO}_{2} \mathrm{GeoNet}$ is to enable safe and efficient deployment of $\mathrm{CO}_{2}$ Capture and Storage (CCS).

\subsubsection{Membership}

$\mathrm{CO}_{2} \mathrm{GeoNet}$ is the European scientific body on $\mathrm{CO}_{2}$ geological storage. The nonprofit scientific association currently is comprised by 29 research institutes from 17 European countries. See Figure 1 for details. 


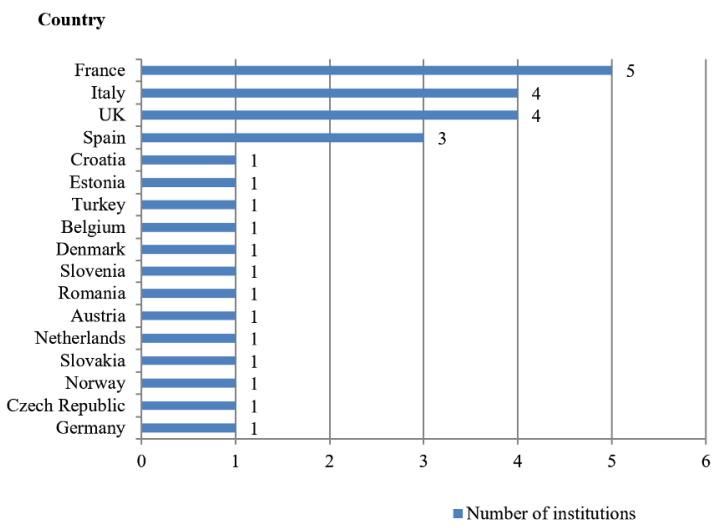

Fig. 1. Number of institutions in each country in $\mathrm{CO}_{2} \mathrm{GeoNet}$.

\subsubsection{Activities}

\subsubsection{Joint Research}

The strategic research aims of the $\mathrm{CO}_{2} \mathrm{GeoNet}$ Association are to produce and disseminate integrated scientific research results, contribute to the identification of knowledge gaps and the formulation of new research targets, and to foster the interaction and exchange of information and views between $\mathrm{CO}_{2}$ storage researchers and CCS stakeholders.

\subsubsection{Scientific Advice}

Scientific advice represents a major channel for $\mathrm{CO}_{2} \mathrm{GeoNet}$ to position itself as a reference body for European science on $\mathrm{CO}_{2}$ Geological Storage. The Association strategy includes the creation of an organized advice system to enable the Network's contribution to advice processes both based on external and own funds.

\subsubsection{Capacity Building}

The $\mathrm{CO}_{2} \mathrm{GeoNet}$ strategy includes training and capacity building to foster the development of upcoming generations of scientists that will be needed for the widespread deployment of the technology.

\subsubsection{Dissemination}

The $\mathrm{CO}_{2} \mathrm{GeoNet}$ strategy includes information and communication as a way to promote the Association and specifically identifies the provision and dissemination of integrated scientific research results and the fostering of the exchange of information and views between $\mathrm{CO}_{2}$ storage researchers and CCS stakeholders.

\subsection{Global CCS Institute (GCCSI)}

\subsubsection{Founded}

Global CCS Institute was Founded in Canberra (Australia) in April, 2009. Officially founded on July 1, 2009. Also referred to as Global Carbon Capture and Storage Institute (GCCSI) of The Institute[4].

\subsubsection{Mission}

The mission of GCCSI is to accelerate the deployment of carbon capture and storage (CCS).

\subsubsection{Membership}

The diverse international membership includes governments, global corporations, private companies, research bodies and nongovernmental organizations; The Global CCS Institute is comprised by 98 research institutes from 19 countries. See Figure 2 for details.

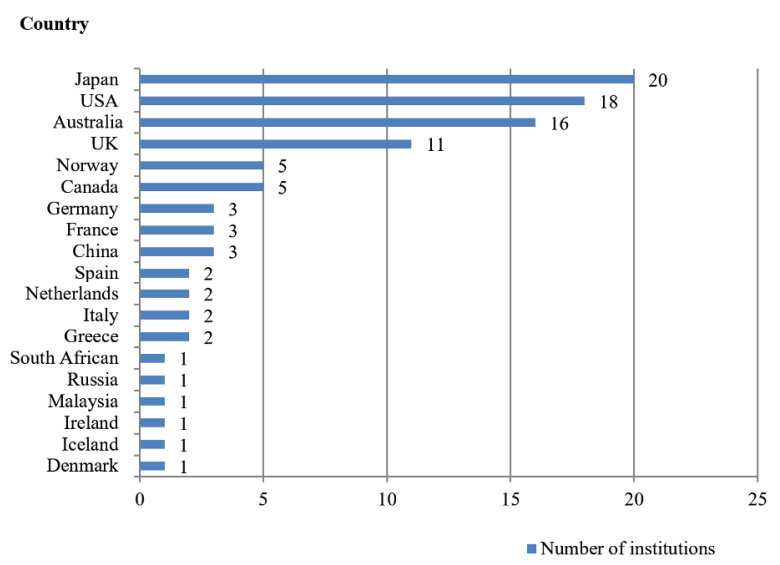

Fig. 2. Number of institutions in each country in GCCSI.

\subsubsection{Activities}

\subsubsection{Build Knowledge}

As the world's leading CCS think tank, it is an unparalleled source of research, data and information on all aspects of CCS deployment. The Global CCS Institute offers expertise and knowledge across every aspect of CCS, providing our members with accurate, insightful and impactful information and data about CCS, assisting them to build knowledge, connect with the right people and make informed business decisions. No other organization has the holistic capabilities or CCS expertise on a global scale. Our team includes geologists, scientists, engineers, economists, policy analysts, climate change experts, business developers and marketers, who provide expertise across the entire CCS spectrum.

\subsubsection{Shift the Narrative}

It promote and build awareness of CCS and its vital role in achieving energy security and emissions reductions targets to key media outlets, policymakers and important influencers around the world. This is critical given the 
proliferation of mis-information regarding the reliability, economics and applicability of CCS.

\subsubsection{Enable Investment}

It works with its members and other businesses and governments, leveraging our CCS knowledge, skills and expertise, to enable investment in the next wave of CCS facilities. As policy and legislative changes create renewed opportunities around the world, now is the time to drive this investment.

\subsection{International Institute for Carbon-Neutral Energy Research (I2CNER)}

\subsubsection{Founded}

International Institute for Carbon-Neutral Energy Research was founded in Fukuoka (Japan) in 2010. Also referred to as ${ }^{2} \mathrm{CNER}[5]$.

\subsubsection{Mission}

The mission of $\mathrm{I}^{2} \mathrm{CNER}$ is to creation of a sustainable and environmentally friendly society by advancing fundamental science to reduce $\mathrm{CO}_{2}$ emissions and establish a non-fossil based energy carrier system.

\subsubsection{Membership}

The Institute is a unique collaborative project between Kyushu University and the University of Illinois at Urbana-Champaign, with the main facility located on the Ito campus in Japan, and a Satellite Institute located in the United States of America.

\subsubsection{Activities}

\subsubsection{Advanced Energy Materials Thrust}

Develop molecular, nano, and bulk materials based on new science of surfaces, interfaces, and microstructures for applications involving $\mathrm{H}_{2}, \mathrm{H}_{2} \mathrm{O}$, and $\mathrm{CO}_{2}$.

\subsubsection{Advanced Energy Conversion Systems Thrust}

Development and evolution of systems which either lower carbon emission, increase energy efficiency, or both.

\subsubsection{Multiscale Science and Engineering for Energy and the Environment Thrust}

Pull together the range of challenges facing Japan's and the world's energy transition, namely the transition from largely fossil fueled energy technology to a carbonneutral or a carbon-free energy supply.

\subsection{Carbon Offsets To Alleviate Poverty (COTAP)}

\subsubsection{Founded}

Carbon Offsets To Alleviate Poverty (COTAP) was Founded in 2011, Registered in the State of California (USA)[6].

\subsubsection{Mission}

The mission of COTAP is to empower individuals and organizations in developed countries to address both climate change and global poverty.

\subsubsection{Membership}

The Institute is an Internationally-oriented national organizations. American Tim Whitley launched COTAP. The COTAP is comprised by 6 research institutes from 2 countries, including five American institutions and one British institution.

\subsubsection{Activities}

\subsubsection{Ecotrust's Trees for Global Benefits (TFGB) project}

Ecotrust's Trees for Global Benefits (TFGB) project, located in the Albertine Rift valley in Uganda, is a smallscale, farmer-led agroforestry program which produces long-term, plan vivo-accredited emissions reductions while measurably improving farmer livelihoods and emphasizing sustainable land-use practices. Uganda, in sub-Saharan East Africa, is among the poorest countries in the world, ranked 163th of 187 countries in the UNDP's 2014 Human Development Index. The TFGB project began as a pilot in the Bushenyi district in 2003, and the pilot's success has led to expansion into the districts of Rubirizi, Mitooma, Kasese, Hoima, and Masindi, as well as into the Mount Elgon ecosystems of Rwenzori, Mbale, Manafwa, Bududa, Bulambuli, and Sironko.

\subsubsection{Taking Root's CommuniTree Project}

Taking Root's CommuniTree Project began near the rural municipality of San Juan de Limay in the province of Esteli, Nicaragua. Nicaragua is the second poorest country in the Americas, after Haiti. As of 2016, Taking Root has partnered with 65 different communities comprising 409 small-scale family farmers and spanning an area of 7,400 hectares. As of the end of the 2016 planting season, the project had cumulatively planted 2.2 million trees.

\subsubsection{The Khasi Hills Community REDD+ Project}

The Khasi Hills Community REDD+ Project is located in the remote northeast state of Meghalaya with Bangladesh to the south and Bhutan to the north. 
Spanning 27,000 hectares, it deploys strategies for both forest protection (Reducing Emissions from Deforestation and Forest Degradation, or "REDD") and restoration (Assisted Natural Regeneration, or "ANR"). The project also provides detailed and long-term plans for improving the livelihoods of 4,400 households, $80 \%$ to $90 \%$ of which live below the poverty line. The region experienced a rapid 28\% loss in forest cover between 2000 and 2005. Further, India ranks 136th of 186 countries in the UNDP's 2012 Human Development Index, and annual incomes in the region are $\$ 490$ for a family of 5 to 6 .

\subsubsection{Envirotrade's Sofala Community Carbon Project}

Envirotrade's Sofala Community Carbon Project is located in the buffer zones around Gorongosa and Marromeu National Parks in the central Sofala province of Mozambique. Mozambique, in sub-Saharan East Africa, is among the poorest countries in the world, ranked 184th of 187 countries in the UNDP's 2011 Human Development Index. Its 16-year civil war, which ended in 1992, left it one of the poorest countries in the world, cost the lives of an estimated 1 million of its citizens, and resulted in significant environmental degradation.To address these difficult challenges, the Sofala project was started as a pilot in 2002 by Envirotrade, the University of Edinburgh, and the European Union with 53 farmers in the wards of N'hambita and Munhanganha.

\subsection{International Sustainability and Carbon Certification (ISCC)}

\subsubsection{Founded}

Current statutes adopted in February, 2011. Registered in accordance with German law[7].

\subsubsection{Mission}

The mission of ISCC is to contribute to the implementation of environmentally, socially and economically sustainable production and use of all kinds of biomass in global supply chains.

\subsubsection{Membership}

The ISCC is comprised by 171 research institutes from 33 countries. Among them, there are 23 countries with two or more institutions, see Figure 3 for details. There are 10 countries with only one institution, including Australia, Colombia, Denmark, Greece, Hungary, Iceland, Ireland, Lithuania, Slovakia, and South Korea.

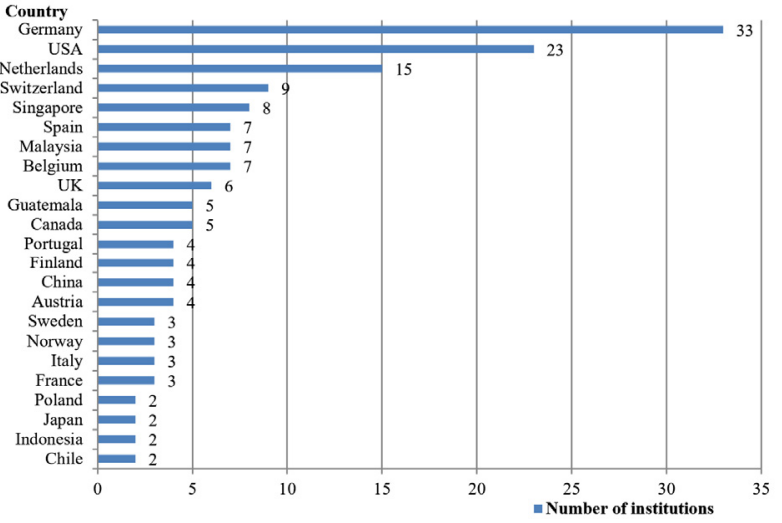

Fig. 3. Countries with 2 or more institutions in ISCC.

\subsubsection{Activities}

\subsubsection{Governance \& Transparency}

ISCC has set up a working group to improve the transparency of ISCC by mandatory publication of summary audit reports. The set up of the working group was agreed at the General Assembly 2016 with the scope to elaborate a summary audit report that should be made publicly available for each issued certificate. The working group had to consider a trade-off between enhancing the transparency of ISCC and protecting sensitive company information.

\subsubsection{Food Security}

ISCC is partner of the Food Security Standard (FSS). By adopting the FSS, companies along the value chain can now demonstrate that they are committed to the Human Right to adequate Food and the UN Sustainable Development Goals (SDGs).

\subsubsection{Sustainable Development Goals}

ISCC supports the Sustainable Development Goals. The 2030 Agenda for Sustainable Development adopted by all UN Member States in 2015 aims to foster peace and prosperity for people and the planet, today and in the future. At its heart are the 17 Sustainable Development Goals (SDGs) which call for climate action, environmental conservation, an end to poverty, improved health and education, reduced inequality and economic growth. Especially the private sector is called upon to contribute to a sustainable development. Therefore, ISCC supports businesses to act more responsibly and secure sustainability throughout the entire supply chain. However, ISCC is aware of the challenges and seeks to continuously improve its contribution to the fulfilment of the SDGs.

\subsubsection{Circular Economy and Bioeconomy}

ISCC supports the transition to a circular economy and bioeconomy. 


\subsubsection{Benchmarking}

SCC regularly participates in benchmarking processes comparing different systems for sustainability certification. ISCC uses the results of those processes and the feedback provided to learn and improve continuously.

\subsubsection{Sustainable Aviation Fuels}

As a well-experienced sustainability certification scheme, ISCC can guarantee compliance and enhance traceability through site-specific audits. ISCC's vast experience in road transportation is of high value when it comes to certifying sustainable aviation fuels. Since large volumes of certified feedstock are already available and many major fuel producers are ISCC members, SAF certification with ISCC is feasible and practical.

\subsection{Carbon Neutral Cities Alliance (CNCA)}

\subsubsection{Founded}

The Carbon Neutral Cities Alliance (CNCA or "Alliance") was born in Copenhagen in June 2014[8].

\subsubsection{Mission}

The mission of CNCA is to enable leading cities worldwide that are working aggressively toward a zerocarbon future to advance their own transformational efforts, collaborate with each other and key partners to overcome barriers, foster innovative approaches, and share lessons with other cities ready to pursue similar goals.

\subsubsection{Membership}

At present, the alliance has attracted 22 cities from 13 countries to participate in carbon neutrality. See Figure 4 for details.

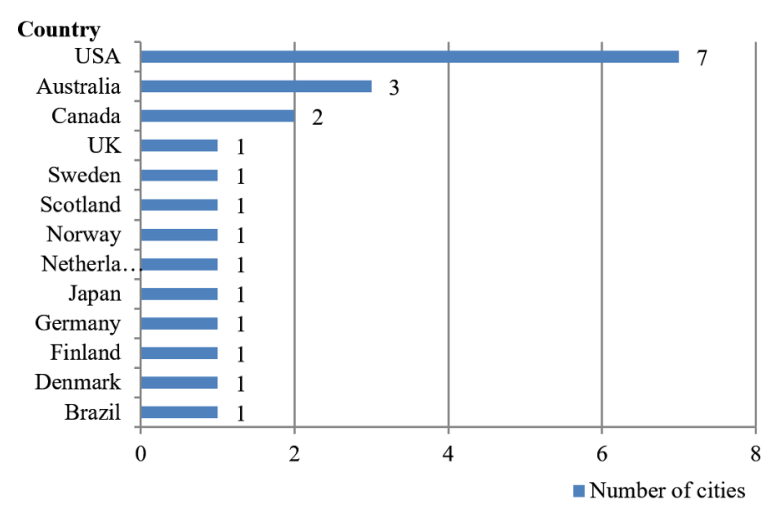

Fig. 4. Number of cities in each country in CNCA.
Developing approaches, analysis, and tools to support carbon neutrality; standardizing measurement and verification methodologies for tracking progress.

\subsubsection{Advancing "Transformative Change" in Key Urban Sectors}

Sharing and implementing best practices for achieving "transformative" deep carbon reduction strategies in urban transportation, energy use, and waste systems.

\subsubsection{Advocating for Policy Change}

Identifying and advocating for policies at the state, regional, and federal levels to reduce emission sources not controlled directly by cities and engaging with other external stakeholders who are critical to cities' success.

\subsubsection{Speaking with a Common Voice}

Helping CNCA cities demonstrate their leadership and communicate with a common voice.

\subsubsection{Creating a CNCA "Innovation Fund"}

Investing in high-potential, city-led projects that develop, test, implement, and amplify deep decarbonization strategies and practices.

\subsubsection{Increasing Alliance Impact}

Sharing Alliance learnings with a broader audience to benefit the "next wave" of cities striving for carbon neutrality.

\section{Conclusions}

The goal of six carbon neutral international organizations is to offset carbon dioxide emissions through afforestation, energy conservation and emission reduction, so as to achieve "zero emission" of carbon dioxide and contribute to the creation of a sustainable and environment-friendly society.

Among the six carbon neutral international organizations, most of the institutions and cities are from the United States, Germany, Australia, Japan and the United Kingdom.

\section{Acknowledgements}

This paper is supported by China Geological Survey Project "Update and service of geoscience literature information" (DD20190413).

\subsubsection{Activities}

\subsubsection{Developing Carbon Neutrality Planning Standards}




\section{References}

1. Xi J P. Speech at the general debate of the seventyfifth United Nations General Assembly [N]. The People's Daily, 2020-09-23 (in Chinese)

2. https://ybio.brillonline.com/ybio/,2021-5-10.

3. http://www.co2geonet.com/,2021-5-12.
4. https://www.globalccsinstitute.com ,2021-5-12.

5. http://i2cner.illinois.edu/,2021-5-12.

6. http://cotap.org/, 2021-5-12.

7. http://www.iscc-system.org/ ,2021-5-12.

8. https://carbonneutralcities.org/ ,2021-5-12. 